\title{
Review on Crop Regulation and Cropping Techniques on Guava
}

\author{
Himaja Das* \\ Lovely Professional University, Phagwara, Punjab, India \\ *Corresponding author
}

\begin{tabular}{l} 
Ke y w o r d s \\
$\begin{array}{l}\text { Guava,Flower, } \\
\text { Quality and } \\
\text { Quantity }\end{array}$ \\
Article Info \\
\hline $\begin{array}{l}\text { Accepted: } \\
\text { 10 November } 2020 \\
\text { Available Online: } \\
10 \text { December } 2020\end{array}$ \\
\hline
\end{tabular}

A B S T R A C T

Guava is considered as the poor man's apple which is the most key fruit crop in India and found to be the Myrtaceae family. guava has an important nutritional value in fruits and leaves. Guava is becoming popular these days because of its inherent nutritional value. The fruits that are harvested during the rainy season have less value due to their aquatic nature present in the fruits. The fruits have a higher value on the market, which is harvested during the winter season, as the fruits have a better edible portion, better fruit quality, and organoleptic taste. To achieve crop regulation, he must achieve proper techniques such as stopping irrigation, thinning of flower buds, germination of pruning, and various chemical applications. To normalize the guava harvest of fruit, it is important to cut the fruit for the duration of the winter season. A high-quality harvest is only achievable because the harvest is harvested for only one season in Bihar.

\section{Introduction}

Guava (Psidium guajava L) is India's fifth most important fruit crop and is highly regarded in the tropical and subtropical regions of the world. Due to its high nutritional value, it is easily available at a reasonable price named after the apple of the tropics and superfruit (Nimisha et al., 2013, Parvez et al., 1999). Smith (1934) states that by harvesting only in winter, the number of fruits given per year will increase. There are three flowering seasons: spring (Ambebahar), rain (Murigubahar), and fall (Hastabahar), and harvest seasons are corresponding to the monsoon season, the winter season, and the spring season of Guava.(Singh and Rathore 1974). The seasonal guava crop is rough, tasteless, poor quality, less nutritious and is attacked by various pests and diseases (Radha and Mathew et al., 2007).

The fruits of the winter season are of the highest quality, No diseases and pests, and get more prices on the market. The harvest in the winter season has a better shelf life. And so 
they are often transported to their destination at reasonable prices (Nautiyal, 2016).

Monselise and Goldschmidt (1982) confirmed that sprout grows very faster in the first 4 months, sunken over the next three months, and finally, drying began. Guava fruits contain many antioxidant properties and are known to regulate blood pressure. The most intense flowering is observed mainly in the harvest of the rainy season due to the abundant humidity and the appearance of buds that bear fruit in the axils of leaves and fruits. The most drastic part of the fruit is observed in the fruits of the rainy season. The fruits of the rainy season have bristly, rough, poor quality and less nutritious taste and are attacked by many pests, insects, and diseases. But the fruits of the winter season are better in size, quality, taste, and aroma, and the chances of insects, pests, and diseases are low, and the price is comparable to the harvest of the rainy season. This crop has been the subject of several rainforest reduction studies to strengthen the winter harvest by exposing and pruning roots, pruning shoots, thinning and chemical thinning using urea and growth substances such as Naphthalene Acid Amide (NAD), 2-4 dichlorophenoxyacetic acid, etc. and also some other methods, such as stopping the irrigation water, dripping the leaves, etc. It is also practiced by researchers. Flowering is more guava during the summer season due to the new strong waves, leading to more fruit production during the monsoon season. During this season, high temperatures and rain shorten the fruit harvest period by 30 days, creating a surplus in the market and leading to poor fruit quality and low prices, and lower market demand. The harvest during the winter season is of the highest quality, which requires high prices on the market, for now, obtaining quality fruit in guava only during the winter season.
The fruits of the winter season are of the highest quality, without pets, and reach higher prices on the market. The harvest during the winter season has a better shelf life, so it is often transported to its destination at reasonable prices (Nautiyal et al., 2016).

Fertilizers should be applied 15 days before bending the branches again in the pea growth phase, followed by irrigation (Singh, 2013). To avoid the unwanted and to take the desired seasonal harvest, various techniques such as stopping irrigation, thinning the buds, pruning the shoots, and then applying various chemicals (Singh et al., 2013) from these treatments have been effective in reducing the seasonal harvest and increase production during the winter season. And it is a hardy, fertile, and highly profitable fruit crop that is widely cultivated in tropical and subtropical regions, it has succeeded in climatic diversity. At high temperature and low humidity, adhesion and fruit growth deteriorate. In tropical climates, due to the presence of sufficient heat and humidity, they produce almost continuous fruit.

The procedure needs to be practiced for crop improvement and its parameters depend on the Environmental aspect, the cultivation pattern, the degree of loss occurred by diseases along with pests, at marketplace and industrial requirement varieties, and further. Crop directives are achieved in the course of dissimilar methods such as irrigation supervision to basis stress, training of shoots and roots at diverse proportions and at various times.

\section{Crop regulation}

In guava, (Singh2000 et al.,) flowering is greater during the sunny period (AmbBahar) as a result of the break of wintry weather stress, that promote larger fruit yield procurement in monsoon season. excluding 
this period, based on high temperatures and rains during the ripening of the fruit, the duration of ripening is reduced to 30 days, which causes a surplus on the market, while the harvest of the (Singh et al., 2000)

Winter (MrigBahar) is of high quality and relatively expensive. But, Production is seasonal (Rathore and Singh, 1974) and of no minimum quality subjected to flavorless and parasite fault (Rawal and Ullasa, 1988) Compared to the cold period. On the opposing, elevated superiority fruits are formed for the period of cold and get a more economical addition (Singh et al., 2000). The peaks of the Guava fruit crop may vary depending on weather conditions and growing practices, as the flowers are produced with new growth. It is therefore advisable to request only the harvest during the winter season of the year. This requires crop development. To reach out the specific required commercial produce, following techniques that are watering, thinning the blooms chemical-based or manual, cutting, bending, exposing the roots, etc. The elementary rule of plant directive is to operate the usual blooming and produce of guava crop in the required season of the annum. This helps increase yield, quality, profitability, and ecological sustainability by dropping the frequency of pesticide use (Jayadevan and Kumar, 2014).

\section{Methods for crop regulation in Guava}

Several methods are trying to provoke a new vegetative phase. Growth during the season to harvest armor in the following cold period(Singh et al., 2000). The effort performed by diverse specialists on plantbased management is considered under several subtitles.

\section{Regulation of crops by pruning}

One of The important features of guava is that it blooms. They occur in newly emerging side shoots at any time (Rathore and Singh, 1974) and are suitable for pruning for a variety of purposes. As an outcome, blooming and fruiting come into sight all annual period .It may be infrequent or migratory, based on how the situation affects plant shoot enlargement. cutting has its factors of physiological based first and foremost through changes in the circulation of mineral deposits. Change the sink settings of Bahar Water stress blooming Fruiting AmbeBahar (Feb) Dec-Jan, Feb-Mar, July-Aug MrigBahar (June) Aug-Sept October-November March-April HastaBahar (Oct) Third week of April June-July November-December.

\section{Regulation of aquatic stress crops}

In the northern plains, Mrig-Bahar is preferred to both Hast-Bahars, which makes it required to manage blooming so that Mrigbahar can give abundant flowering and the produce are obtainable in cold time. The subsequent process for captivating MrigBaharis reducing water supply to trees moreover must not be watered from Feb to mid-May. In this way, the tree sheds its leaves during the hot season (April-May) and goes on vacation. During this rest, the tree can store nutrient material in its branches (Pedapati et al., 2015).

In-plant Guava, practices to keep hold ofthe water, to uncover beneficial roots, and cut fibrous roots which might bloom in the required period are taken in Mumbai (Niranjan Singh et al., 2018). Pressure is exposed on the trees by water withholding from Jan to June, and after that, the unloaded control plants are irrigated at regular intervals of 10 to 15 days, based on evaporation.

Flower abscissa is noted when the relative water content reaches 60.20 percent in "Allahabad Safeda" and 53.40 percent in "Sardar" guava. A trend in the amount of leaf proline has also been noted considering the 
scale of irrigational pressure (Singh et al., 1997). In several places of Maharashtra, the roots are exposed and the Minute roots are cut and watering is delayed, so Leave the leaves free. The pools are then covered with manure and soil and abundantly irrigated (Kumar et al., 2010).

Similarly, (Singh et al., 1963) recommended water retention for those areas in the West Indies where soils are lighter. However, root pruning is recommended in addition to water retention in December or January for heavier soils. In Guava, water retention, food root exposure, and fibrous root pruning operations are practiced to force flowering in the desired season. Exposure of roots and pruning of roots. The roots of the plant are exposed to the sun, removing up to $7-10 \mathrm{~cm}$ of soil around the radius of the stem of $40-60 \mathrm{~cm}$. The water is retained for a month or two before flowering. Due to water stress, the leaves dry out and fall to the bottom. Within a month of the beginning of the blooming of the required Bahar, the roots are once more enclosed with a combination of topsoil and farmyard manure instantly irrigated. following irrigation is carried out at appropriate intervals. As a result, the trees give novel vegetative development, plentiful blooming, and yield. Yet the other hand in the light, shallow sandy soils, root disclosure must not be encouraged, and purely with holding water for Two to Three weeks is enough to dry out and deplete the trees. It depends when choosing a producer, which of the three allspices should be taken to achieve maximum profit. As water availability can be a problem in central India From Apr to May, farmers have a first choice on MrigBahar (June), so the trees require to relax from April to May and don't require any water throughout the phase (Cheema et al., 1954) description that uncovering and root cuttings repeatedly hold back the period. Collect this way and get a fair winter crop in guava. Radha and Mathew (2007) propose this the upper part of the soil surrounding the trunk and the diameter of about $90-120 \mathrm{~cm}$ is removed to show the roots. Later than regarding Three to Four weeks, the uncovered roots are roofed with earth, Followed by fertilization and watering. Pruning roots is the practice of removing part of the age of the tree roots or cutting the roots of the tree down to the bottom.

Around the circumference of the shaft on the dripline, pruning is rarely actually recommended or accepted, except when collecting and planting trees from the nursery. within a stable place (Hussein, 2006) uses four pruning practice in guava, specifically cutting 20 percent and 40 percent of the whole leaves, pruning the roots, and then combining 30 percent removing the leaves plus pruning the roots and revealing that each pruning technique is led to significant results larger increases in plant height and stem diameter compared to the control. No clear pattern is observed concerning previous development parameters in circumstances of leaves number and comparative growth rate; however, root cutting gives elevated values than other treatments. The roots are uncovered and the small roots are cut off and watering is delayed so that the leaves can be cut.

\section{With compaction irrigation}

In Guava, the operations of water retention, exposure of the nourishing roots, and pruning of the fibrous roots until the flowering of the Force within the desired season are practiced in Mumbai and the Dean. Root cutting is not suggested in the state of UP, as it creates tension of stress from moisture, leading to leaf fall and crop growth disruption during the unwanted Bahartime (Singh, 2013).

All season treatment is most essential in the southern part central portion and western region of India, where development and 
blooming go on with all over the annum (Naik, 1963). Cheema (1954) suggested water withholding and subtraction of the soil from the higher roots until June 10 and top it with soil and manure. Here 2 irrigations are also offered before the normal intensive, when the rains have not started. Singh (1963) He recommended water retention for those areas in the West Indies where the soils were lighter. For heavier soils, however, we suggest pruning the roots in addition to stopping the water in December or January.

\section{Thinning by hands}

It is possible to manage the cultivation model in Guava by manually thinning the buds and thinning the flowers in March and April for the varieties Red Flushed, Allahabad Safeda, and Sardar, which showed to be on the whole efficient in dropping the size, collected during the rainy season by water retention (Singh and Singh, 2011).

\section{Bending of guava crops for crop regulation}

Most West Bengal growers prefer the winter harvest and regulate flowering by folding and spreading. Shoots until August-September (Mitra et al., 2008). This practice is closely related to the shaping of guava branches. The design of scheming the usual blooming of the branches of guava plants. They fold about 45 to 60 days before the expected blooming date and to bear fruit out of season. The first time you bend the branches of the guava plant. It should be used at the age of two years on the plant. Before folding the leaves, remove the small shoots, flowers, and fruits from the branch or stop keeping the 10-12 inch end twigs intact. In the fall (Sept-Nov) it takes 2025 days for the new photoshoot. Curved branches should be loose when The new shoots are about $1 \mathrm{~cm}$ long. Blooming occurs inside the new leaves of shoots with 4 to 5 pairs of leaves. After 45-50 days in summer and 60 to 65 days in autumn. Fertilizer and fertilizers should be applied 15 days before the bending of the branches and again in the growth phase of the pea, followed by irrigation (Singh, 2013).

In conclusion, the regulation of guava crops is often successfully adopted by various cultural and chemical methods. Among the best methods of cultivation were pruning in the middle of the shoots of the current season and manual removal of blooming at fifty percent of the summer season in May. Among the synthesized plus foliar submissions of 15 percent urea and Naphthalene acetic acid at 200 to $250 \mathrm{ppm}$ are essentially efficient. Based on the accessibility of workers and synthetic chemicals, appropriate techniques have to be accessed to accomplish greater measure and excellent taste flavor of guava orchards.

\section{References}

Cheema GS, Bhat SS and Naik KC (1954). Commercial fruits of India with special reference to western India. Macmillan and Co Ltd.

Kumar, N. (2010).Introduction to horticulture. Oxford \& IBH publishing co.pvt. Ltd, New Delhi

Mitra SK, Gurung MR and Pathak PK (2008). Sustainable guava production in West Bengal, India. ActaHorticulturae 773: 179-182.

Naik KC (1963) South Indian fruits and their culture. P Varadachary and Co, Madras, Tamil Nadu, India

Nautiyal P, Lal S, Dimri DC and Arora I (2016). Shoot pruning severity in high density of guava (Psidium guajava L). International Journal of Agriculture Sciences 8(52): 2427-2431.

Nimisha S, Kherwar D, Ajay KM, Singh B and Usha K (2013). Molecular breeding to improve guava (Psidium guajava $L$ ): 
current status and future prospective. Scientia Horticulturae 164: 578-588.

Niranjan Singh, DP Sharma, Sudarshakumari and Kapilkalsi (2018).Techniques for crop regulation in guava- a review. International Journal of Farm Sciences 8(2): 131-135.

Parvez MA, Muhammad F. and Ahmad M. (1999). Scientific approach to enhance the income from guava orchards. Pakistan Journal of Biological Sciences 2(4): 1637-1638.

Radha T and Mathew L (2007). Fruit crops. Horticulture Science Series- 3 (KV Peter ed), New Delhi Publishing Agency, New Delhi, India.

Rathore DS and Singh RN (1974). Flowering and fruiting in three cropping patterns of guava. Indian Journal of Horticulture 31(4): 331-336.

Rawal, R.D. and Ullasa, B.A. (1988). Management of fruit diseases of guava Psidium guajava $L$. Through fungicidal sprays. Indian J. Agric. Sci., 58:950-52. Singh G (2013). Guava. Westuille Publication
House, New Delhi, India.

Singh G, Singh, AK. And Verma, A. (2000). Economic evaluation of crop regulation treatments in guava (Psidium guajava L). Indian Journal of Agricultural Sciences 70(4): 226-230.

Singh, G., and Reddy, Y.T.N. (1997). Regulation of Cropping in guava. Indian J. Hort., 54:44-49.

Singh, G., Singh, A.K. and Pandey, D. (2000). Effect of cropping pattern on fruiting behaviour of guava (Psidium guajava L.). Tree Am. Agric. Res, 22:175-82.

Singh R (1963). Fruits. National Book Trust, New Delhi, India, pp 135-144.

Singh S and Singh J (2011). Regulation of cropping in guava. Orissa Journal of Horticulture 29(2): 97-99.

Smith WS (1934). The guava. Fruit Series Bullettin \# 8, Department of Agriculture, Uttar Pradesh, India.

\section{How to cite this article:}

Himaja Das. 2020. Review on Crop Regulation and Cropping Techniques on Guava. Int.J.Curr.Microbiol.App.Sci. 9(12): 1221-1226. doi: https://doi.org/10.20546/ijcmas.2020.912.150 